\title{
Pengaruh penambahan aluminium oksida terhadap kekuatan tarik dan tekan basis gigi tiruan resin akrilik polimerisasi panas
}

\author{
Actara Rahmadita ${ }^{1 *}$, Dwi Tjahyaning Putranti ${ }^{1}$ \\ 'Departemen Prostodonsia, Fakultas Kedokteran Gigi, Universitas Sumatera Utara, Indonesia \\ *Korespondensi: actararahmadita60@gmail.com \\ Submisi: 15 Oktober 2018; Penerimaan: 23 November 2018; Publikasi online: 31 Desember 2018 \\ DOI: $\underline{10.24198 / j k g . v 30 i 3.18994}$
}

\begin{abstract}
ABSTRAK
Pendahuluan: Resin akrilik polimerisasi panas (RAPP) merupakan bahan basis gigi tiruan yang paling banyak digunakan, namun memiliki sifat kekuatan tarik dan tekan yang rendah, sehingga diperlukan modifikasi dengan penambahan bahan penguat pada RAPP berupa aluminium oksida $\left(\mathrm{Al}_{2} \mathrm{O}_{3}\right)$ atau alumina. Tujuan penelitian untuk menganalisis pengaruh penambahan aluminium oksida pada bahan basis gigi tiruan RAPP terhadap kekuatan tarik dan tekan. Metode: Jenis penelitian eksperimental laboratoris. Sebanyak 25 sampel berbentuk flat dumbbell shaped berukuran $60 \times 12 \times 3,9(\mathrm{~mm})$ untuk uji kekuatan tarik dan 25

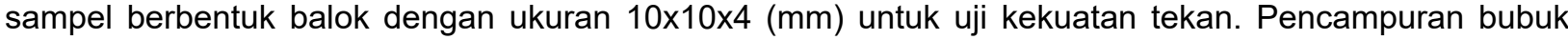
resin-aluminium oksida konsentasi $0,5 \%, 1,5 \%, 2,5 \%$ dan $3,5 \%$ dengan cairan resin dilakukan secara manual. Sampel direndam dalam air dan dimasukkan ke dalam inkubator. Uji dilakukan menggunakan universal testing machine dengan beban $1000 \mathrm{~N}$ dan kecepatan crosshead $1 \mathrm{~mm} / \mathrm{menit}$. Data dianalisis dengan uji ANOVA satu arah dan uji $L S D$. Hasil: Nilai kekuatan tarik kelompok kontrol dan keempat kelompok perlakuan penambahan aluminium oksida 0,5\%, 1,5\%, 2,5\%,3,5\% berturut turut adalah 50,867 $\mathrm{MPa}, 47,895 \mathrm{MPa}$, 45,107 MPa, 42,476 MPa, dan 39,753 MPa; sedangkan nilai kekuatan tekan kelompok kontrol dan keempat kelompok perlakuan penambahan aluminium oksida $0,5 \%, 1,5 \%, 2,5 \%, 3,5 \%$ berturut turut adalah 88,267 MPa, 106,085 MPa, 122,283 MPa, 135,367 MPa, dan 156,571 MPa. Penambahan bubuk aluminium oksida pada RAPP dapat menurunkan kekuatan tarik dan meningkatkan kekuatan tekan secara signifikan $(p=0,0001(p<0,05))$, seiring dengan meningkatnya jumlah konsentrasi aluminium oksida yang ditambahkan. Simpulan: Penambahan aluminium oksida pada bahan basis gigi tiruan resin akrilik polimerisasi panas berpengaruh terhadap kekuatan tarik dan tekan.
\end{abstract}

Kata kunci: Resin akrilik polimerisasi panas, aluminium oksida, kekuatan tarik, kekuatan tekan

The effect of addition of aluminium oxide on the tensile and compressive strength of a heat-polymerised acrylic resin denture base

\section{ABSTRACT}

Introduction: Heat-polymerised acrylic resin (HPAR) is the most widely used denture base material but has a low tensile and compressive strength thus modification is needed by adding reinforcement in the form of aluminium oxide $\left(\mathrm{Al}_{2} \mathrm{O}_{3}\right)$ or alumina. The research objective was to analyse the effect of adding aluminium oxide on the tensile and compressive strength of HPAR denture base material. Methods: An experimental laboratory research was conducted towards the total of 25 samples in the form of flat dumbbell shape sized $60 \times 12 \times 3.9 \mathrm{~mm}$ for the tensile strength test, and 25 samples in the form of blocks with the size of $10 \times 10 \times 4 \mathrm{~mm}$ for the compressive strength test. The mixture of powdered aluminium oxide resin with the concentrations of $0.5 \%, 1.5 \%, 2.5 \%$, and $3.5 \%$ with a liquid resin was carried out manually. The sample was then immersed in the water and put in an incubator. The test was performed using a universal testing machine with $1000 \mathrm{~N}$ loads and $1 \mathrm{~mm} /$ minute crosshead speed. Data obtained were analysed using the one-way ANOVA and LSD test. Result: The tensile strength values of the control group and all four treatment groups added with $0.5 \%, 1.5 \%, 2.5 \%$, and $3.5 \%$ aluminum oxide were $50.867 \mathrm{MPa}, 47.895 \mathrm{MPa}$, 45.107 MPa, 42.4476 MPa and 39.753 MPa respectively, while the compressive strength values were 88.267 MPa, 106.085, 122.283 MPa, 135.367 MPa, and 156.571 MPa consecutively. Addition of aluminium oxide powder to the HPAR can significantly reduce the tensile and compressive strength $(p=0.0001(p<$ 0.05)) along with increasing concentration. Conclusion: Addition of aluminium oxide towards the HPAR denture base affected its tensile and compressive strength. 


\section{PENDAHULUAN}

Basis gigi tiruan merupakan bagian dari gigi tiruan yang bersandar pada jaringan lunak tanpa mengganggu pergerakan pipi dan lidah serta sebagai tempat melekatnya gigi tiruan. Basis gigi tiruan membantu menyalurkan semua tekanan yang bekerja pada gigi tiruan ke jaringan basal..$^{1,2}$ Basis gigi tiruan terbagi dua, yaitu basis gigi tiruan logam dan non logam. Salah satu jenis gigi tiruan non logam adalah resin. Berdasarkan sifat termalnya, resin dibagi menjadi termoplastik dan termoset. Contoh resin jenis termoplastik antara lain yaitu poliester dan nilon termoplastik dan contoh resin yang tergolong termoset adalah resin akrilik. ${ }^{3,4}$

Resin akrilik atau polimetil metakrilat pertama kali ditemukan pada tahun 1937 oleh Wright. Resin akrilik merupakan bahan yang paling banyak digunakan sebagai bahan basis gigi tiruan pada tahun 1946, terutama resin akrilik polimerisasi panas. Resin akrilik polimerisasi panas hampir memenuhi semua persyaratan sebagai basis gigi tiruan yang baik. ${ }^{5}$ Resin akrilik polimerisasi panas memiliki sifat estetis yang baik, mudah diperbaiki, mudah untuk diproses, dan harganya relatif murah. Meskipun demikian, RAPP memiliki kekurangan pada sifat mekanis dan fisis, sehingga mudah patah saat terjatuh atau karena tingginya tekanan pengunyahan yang diterima basis gigi tiruan. Hal ini dapat menyebabkan kegagalan ketika jatuh atau selama proses pengunyahan oleh pasien. Selain itu RAPP dapat menyebabkan alergi dan memiliki konduktifitas termal yang rendah, sehingga dapat menyebabkan berkurangnya persepsi rasa pada pasien. ${ }^{2,6-8}$ Salah satu sifat mekanis basis gigi tiruan RAPP adalah kekuatan tarik dan tekan. Nilai kekuatan tarik RAPP adalah sebesar $52 \mathrm{MPa} .3,4,7,9$ Kekuatan tarik berhubungan dengan keretakan pada basis gigi tiruan yang disebabkan karena kebiasaan pasien yang sering melepaskan gigi tiruan. ${ }^{10}$ Sedangkan kekuatan tekan adalah tekanan tekan yang diberikan pada benda sampai pada titik terjadinya fraktur. Nilai kekuatan tekan RAPP adalah 75 Mpa berdasarkan American Society for Testing and Material (ASTM D 638). ${ }^{3}$ Kekuatan tekan sangat penting karena dapat berpengaruh terhadap besarnya kekuatan pengunyahan yang digunakan oleh pasien. ${ }^{11}$

Penambahan bahan pengisi berupa logam oksidapada RAPP mempengaruhi sifat fisis, mekanis serta biologis basis gigi tiruan RAPP. Logam oksida yang sering ditambahkan pada RAPP adalah aluminium oksida $\left(\mathrm{Al}_{2} \mathrm{O}_{3}\right)^{8,12}$ Aluminium oksidadisebut juga dengan alumina. Alumina memiliki ikatan interatomik ion yang kuat, sehingga dapat meningkatkan sifat material yang diinginkan. ${ }^{8,9}$ Aluminium oksida merupakan material yang biokompatibel, memiliki densitas rendah, dan ringan sehingga keuntungan RAPP dapat dipertahankan. Meskipun berwarna putih, bubuk aluminium oksida tidak mempengaruhi estetis bahan basis gigi tiruan dari RAPP. ${ }^{8,13}$

Abdulhamed AN $\mathrm{dkk}^{8}$ menambahkan $\mathrm{Al}_{2} \mathrm{O}_{3}$ dengan konsentrasi $5 \%, 7,5 \%$, dan $10 \%$ ke dalam RAPP, menurunkan kekuatan tarik RAPP. Penurunan kekuatan tarik ini dapat terjadi karena kurangnya pembasahan bahan pengisi oleh cairan resin, sehingga dapat menurunkan kekuatan tarik. Sehajpal SB dkk ${ }^{14}$ menambahkan aluminium oksida pada RAPP dengan konsentrasi $5 \%, 10 \%$, $15 \%, 20 \%$, dan $25 \%$ sehingga terjadi penurunan kekuatan tarik hingga $27,3 \%$ dan peningkatan kekuatan tekan hingga 9,9\% ketika ditambah aluminium oksida $25 \%$ jika dibandingkan dengan RAPP tanpa penambahan aluminium oksida. Tujuan penelitian ini adalah untuk mengetahui pengaruh penambahan aluminium oksida pada bahan basis gigi tiruan RAPP terhadap kekuatan tarik dan tekan.

\section{METODE}

Rancangan penelitian yang digunakan adalah eksperimental laboratories. Desain penelitian yang digunakan adalah post only with control group design. Ukuran model induk dari logam yang akan digunakan untuk uji kekutan tarik menurut ISO 5271 adalah dengan bentuk flat dumbbell-shaped dengan ukuran panjang $60 \mathrm{~mm}$, lebar $12 \mathrm{~mm}$, dan tebal $3,9 \mathrm{~mm}$. Ukuran model induk dari logam yang akan digunakan untuk pengujian kekuatan tekan menurut ISO 604 adalah dengan panjang $10 \pm 0,2 \mathrm{~mm}$, lebar $10 \pm 0,2 \mathrm{~mm}$ dan tebal $4 \pm 0,2 \mathrm{~mm}$. Sampel pada penelitian ini adalah bahan basis gigi tiruan resin akrilik polimerisasi panas tanpa penambahan bahan penguat sebagai kontrol dan bahan basis gigi tiruan resin akrilik polimerisasi panas dengan penambahan 
aluminium oksida Beta Diamond Products dengan empat kelompok konsentrasi yang berbeda yaitu $0,5 \%, 1,5 \%, 2,5 \%$ dan $3,5 \%$. Bubuk aluminium oksida yang telah ditimbang dicampurkan dengan bubuk RAPP menggunakan penanganan manual dengan lumpang dan alu hingga warna tercampur dengan rata. Bubuk aluminium oksida-polimer yang sudah tercampur dipindahkan kedalam pot akrilik dan dicampur dengan cairan resin. Pencampuran bubuk aluminium oksida-polimer dengan cairan RAPP yaitu dengan perbandingan 2:1 berdasarkan berat. Adonan yang telah mencapai fase dough dimasukkan kedalam mold. Besar tekanan pengepresan yang digunakan adalah 500 psi pada pengepresan pertama dan dilanjutkan dengan tekanan 1000 psi pada pengepresan kedua. Proses kuring dilakukan dengan menggunakan waterbath dengan suhu $70^{\circ} \mathrm{C}$ selama 90 menit dan dilanjutkan dengan suhu $100^{\circ} \mathrm{C}$ selama 30 menit. Sampel yang telah dirapikan direndam di dalam inkubator selama 48 jam pada suhu $37^{\circ} \mathrm{C}$. Sampel diuji dengan menggunakan Universal Testing Machine (UTM) dengan beban $1000 \mathrm{~N}$ dan kecepatan crosshead $1 \mathrm{~mm} /$ menit. Tarikon AND RTF-1350, Japan).

Data diperoleh dengan uji ANOVA satu arah dan uji LSD untuk melihat pasangan mana yang paling bermakna antar kelompok yang diuji.

\section{HASIL}

Tabel 1 menunjukkan nilai kekuatan tarik RAPP tanpa penambahan aluminium oksida adalah 50,867 MPa. Kelompok dengan penambahan aluminium oksida $0,5 \%$, nilai kekuatan tarik adalah 47,895 MPa. Kelompok dengan penambahan aluminium oksida 1,5\% adalah 45,107 MPa. Pada kelompok dengan penambahan aluminium oksida 2,5\% adalah 42,476 MPa. Kelompok dengan penambahan aluminium oksida $3,5 \%$ didapatkan nilai kekuatan tarik sebesar $39,753 \mathrm{MPa}$. Hasil uji ANOVA satu arah, menunjukkan terdapat pengaruh yang signifikan dalam penambahan aluminium oksida $0,5 \%, 1,5 \%, 2,5 \%, 3,5 \%$ terhadap kekuatan tarik $(p=0,0001(p<0,05))$.

Hasil uji LSD menunjukkan ada perbedaan pengaruh yang signifikan antara kelompok tanpa penambahan aluminium oksida dengan kelompok penambahan aluminium oksida dengan
Tabel 1. Pengaruh penambahan aluminium oksida masingmasing dengan konsentrasi $0,5 \%, 1,5 \%, 2,5 \%$, dan $3,5 \%$ pada bahan basis gigi tiruan resin akrilik polimerisasi panas terhadap kekuatan tarik

\begin{tabular}{lcccc}
\hline \multirow{2}{*}{ Kelompok } & \multicolumn{2}{c}{$\begin{array}{c}\text { Nilai kekuatan tarik } \\
(\mathbf{M P a})\end{array}$} & $\mathbf{p}$ \\
\cline { 2 - 3 } & $\mathbf{n}$ & $\mathbf{\pm}$ SD & \\
\hline Tanpa bahan penguat & 5 & $50,867 \pm 2,003$ & \\
Aluminium Oksida 0,5\% & 5 & $47,895 \pm 0,289$ & \\
Aluminium Oksida 1,5\% & 5 & $45,107 \pm 0,495$ & $0,0001^{*}$ \\
Aluminium Oksida 2,5\% & 5 & $42,476 \pm 0,671$ & \\
Aluminium Oksida 3,5\% & 5 & $39,753 \pm 1,182$ & \\
\hline
\end{tabular}

Keterangan: *Signifikan $(p<0,05)$

Tabel 2. Pengaruh penambahan aluminium oksida masingmasing dengan konsentrasi $0,5 \%, 1,5 \%, 2,5 \%$, dan $3,5 \%$ pada bahan basis gigi tiruan resin akrilik polimerisasi panas terhadap kekuatan tekan

\begin{tabular}{|c|c|c|c|}
\hline \multirow[t]{2}{*}{ Kelompok } & \multicolumn{2}{|c|}{ Nilai kekuatan tekan } & \multirow[t]{2}{*}{$\mathbf{p}$} \\
\hline & $\mathbf{n}$ & $\pm \mathrm{SD}$ & \\
\hline Tanpa bahan penguat & 5 & $88,267 \pm 2,293$ & \\
\hline Aluminium Oksida $0,5 \%$ & 5 & $106,085 \pm 1,971$ & \\
\hline Aluminium Oksida 1,5\% & 5 & $122.283 \pm 2,732$ & $0,0001^{*}$ \\
\hline Aluminium Oksida 2,5\% & 5 & $135,367 \pm 1,825$ & \\
\hline Aluminium Oksida 3,5\% & 5 & $156,571 \pm 1,750$ & \\
\hline
\end{tabular}

konsentrasi masing-masing $0,5 \%, 1,5 \%, 2,5 \%$ dan $3,5 \%$ terhadap kekuatan tarik $(p<0,05)$.

Tabel 2 menunjukkan nilai kekuatan tekan RAPP tanpa penambahan aluminium oksida adalah 88,267 MPa. Pada kelompok dengan penambahan aluminium oksida $0,5 \%$, nilai kekuatan tekan adalah 106,085 MPa. Kelompok dengan penambahan aluminium oksida $1,5 \%$ adalah 45,107 MPa. Pada kelompok dengan penambahan aluminium oksida 2,5\% adalah 122,283 MPa. Kelompok dengan penambahan aluminium oksida $3,5 \%$ didapatkan nilai kekuatan tekan sebesar 135,367 MPa. Hasil uji ANOVA satu arah, menunjukkan terdapat pengaruh yang signifikan dalam penambahan aluminium oksida $0,5 \%, 1,5 \%, 2,5 \%, 3,5 \%$ terhadap kekuatan tekan $(p=0,0001(p<0,05))$.

Hasil uji LSD menunjukkan ada perbedaan pengaruh yang signifikan antara kelompok tanpa penambahan aluminium oksida dengan kelompok penambahan aluminium oksida dengan konsentrasi masing-masing $0,5 \%, 1,5 \%, 2,5 \%$ dan 
$3,5 \%$ terhadap kekuatan tekan $(p<0,05)$.

\section{PEMBAHASAN}

Nilai kekuatan tarik yang bervariasi pada tiap kelompok dipengaruhi oleh beberapa faktor seperti proses pengadukan dilakukan secara manual, sehingga kecepatan dan jumlah pengadukan yang dilakukan tidak dapat dikendalikan dengan sempurna, monomer sisa dan porositas yang tidak terlihat juga dapat memengaruhi nilai kekuatan tarik yang bervariasi. Menurut Elboraey AN dkk $^{15}$ porositas dan monomer sisa yang ada dapat disebabkan oleh proses kuring dengan menggunakan waterbath. Terbuangnya bahan RAPP yang berlebih pada saat dilakukan proses pengepresan menyebabkan konsentrasi bahan penguat dalam RAPP pada setiap sampel kurang tersebar merata. Menurut Alla RK dkk ${ }^{16}$, teknik compression moulding dapat menyebabkan tidak homogennya distribusi bahan penguat di dalam setiap sampel akibat proses pengepresan yang dilakukan. Perbedaan kekuatan tarik pada tiap sampel dalam kelompok juga dapat disebabkan karena proses pemolesan yang dilakukan secara manual menggunakan kertas pasir sehingga menyebabkan kekasaran permukaan pada tiap sampel dapat berbeda. ${ }^{17}$

Nilai kekuatan tekan yang bervariasi pada tiap kelompok dapat disebabkan oleh teknik pembuatan yang dilakukan, yaitu teknik pengadukan yang dilakukan secara manual sehingga kecepatan pengadukan tidak dapat dikendalikan dengan sempurna. Menurut Hashem $\mathrm{M} \mathrm{dkk}^{18}$ kekuatan tekan dipengaruhi oleh derajat polimerisasi dan sifat kristalin. Semakin tinggi derajat polimerisasi dan sifat kristalin, maka semakin tinggi pula kekuatan tekan karena dapat mengurangi porositas atau rongga pada bahan tersebut.

Hasil penelitian menunjukkan penambahan aluminium oksida pada bahan basis gigi tiruan RAPP dapat menurunkan kekuatan tarik dan meningkatkan kekuatan tekan seiring dengan meningkatnya konsentrasi aluminium oksida yang ditambahkan. Hasil penelitian ini sesuai dengan penelitian Abdulhamed AN dkk ${ }^{8}$ didapatkan bahwa penambahan bubuk aluminium oksida sebanyak $5 \%, 7,5 \%$, dan $10 \%$ ke dalam bahan basis gigi tiruan RAPP dapat menurunkan kekuatan tarik RAPP secara signifikan seiring dengan meningkatnya konsentrasi aluminium oksida yang ditambahkan dengan nilai signifikansi $p=0,00$. Hal ini dapat disebabkan karena menurunnya penampang beban matriks polimer dan juga karena kurangnya pembasahan bahan pengisi oleh resin. Adanya partikel pada bahan pengisi akan membentuk sebuah pemusatan tekanan sehingga dapat memengaruhi penyebaran keretakan yang dapat menurunkan kekuatan tarik dari basis gigi tiruan RAPP. ${ }^{8}$ Penelitian ini juga sesuai dengan penelitian yang dilakukan oleh Sehajpal SB dkk $^{14}$ bahwa penambahan aluminium oksida pada bahan basis gigi tiruan RAPP dapat menurunkan kekuatan tarik hingga $27,3 \%$ jika dibandingkan dengan kelompok kontrol ketika ditambahkan aluminium oksida sebanyak $25 \%$. Hal ini dapat disebabkan oleh adanya pemusatan tekanan karena partikel bahan pengisi dan perubahan modulus elastisitas dari bahan basis gigi tiruan RAPP serta menurunnya kekuatan tarik ini juga disebabkan karena meningkatnya ukuran partikel dari bahan pengisi. Selain itu adanya mikro porositas juga dapat menyebabkan menurunnya kekuatan tarik. Pada penelitian yang dilakukan Sehajpal SB $\mathrm{dkk}^{14}$ juga terjadi peningkatan kekuatan tekan ketika ditambahkan bubuk aluminium oksida pada konsentrasi $20 \%$ hingga $25 \%$. Hal ini dapat disebabkan oleh karena partikel bahan pengisi dapat terdistribusi dengan baik dalam matriks polimer sehingga dapat menghentikan keretakan. ${ }^{14}$ Selain itu, hal ini dapat disebabkan karena sifat material yang dimiliki oleh bahan penguat yang ditambahkan serta adanya ikatan antara bahan penguat dengan RAPP, sehingga RAPP yang ditambahkan bahan penguat memiliki kekuatan tekan yang lebih tinggi jika dibandingkan dengan RAPP tanpa bahan penguat. ${ }^{19}$ Menurut Ghaffar $\mathrm{dkk}^{20}$ penambahan bahan pengisi berupa silver nanopartikel (AgNPs) menyebabkan RAPP menjadi lebih brittle jika dibandingkan dengan kelompok kontrol. Semakin brittle sebuah material, maka semakin tinggi pula kekuatan tekannya karena pada kondisi tekan, material yang brittle akan bertindak seperti material yang ductile.

Penambahan bubuk aluminium oksida pada bahan basis gigi tiruan RAPP dapat memberikan hasil akhir yang berbeda. Peningkatan kekuatan berhubungan dengan penyebaran bahan pengisi yang merata di dalam matriks polimer. Kekuatan 
yang menurun dapat disebabkan karena besarnya penurunan penampang beban matriks polimer, perubahan modulus elastisitas RAPP, kurangnya pembasahan bahan pengisi oleh cairan resin. Partikel pada bahan pengisi akan membentuk sebuah pemusatan tekanan sehingga dapat memengaruhi penyebaran keretakan yang dapat menurunkan kekuatan dari basis gigi tiruan RAPP. Selain itu, buruknya ikatan bahan pengisi ke polimer juga dapat menurunkan kekuatan RAPP. 8,14

Perbedaan pengaruh penambahan aluminium oksida terhadap kekuatan tarik dan tekan dapat disebabkan penambahan bahan penguat pada bahan basis gigi tiruan menyebabkan RAPP menjadi lebih brittle jika dibandingkan dengan kelompok kontrol. Semakin brittle sebuah material, maka semakin tinggi pula kekuatan tekannya, sedangkan kekuatan tariknya rendah.

\section{SIMPULAN}

Penambahan aluminium oksida pada bahan basis gigi tiruan resin akrilik polimerisasi panas berpengaruh terhadap kekuatan tarik dan tekan.

\section{DAFTAR PUSTAKA}

1. Rahn AO, Ivanhoe JR, Plummer KD. Textbook of complete dentures. $6^{\text {th }}$ ed. China: People's MEdical Publishing House. 2009. h. 8-9.

2. Alhareb A, Ahmad Z. Effect of A/2O3/ZrO2 reinforcement on the mechanical properties of PMMA denture base. J Reinf Plast Compos 2011;30(1):86-93.

3. George A, Kumar G, Pillay S, Rao S, Sangur R. Basic dental material $2^{\text {nd }}$ ed. New Delhi: Jaypee Brothers Medical Publisher. 2003. h. 13-7, 100-26.

4. Anusavice K, Shen C, Rawls H. Phillip's science of dental materials. $12^{\text {th }}$ ed. Philadelphia: Elsevier. 2012. h. 4, 48-63.

5. Khindria S, Mittal S, Sukhija U. Evolution of denture base material. J Indian Prost Soc 2009;9(2):64-9.

6. Singh J, Dhiman R, Bedi R. Flexible denture base material: $A$ viable alternative to conventional acrylic denture base material. Contemp Clin Dent 2011;2(4):313-7.

7. Arora P, Singh S, Arora V. Effect of alumina addition on properties of polymethyl methacrylate- A comprehensive review. Int J Biotech Trends Technol 2015;9(1):1-7.

8. Abdulhamed A, Mohammed A. Evaluation of thermal conductivity of alumina reinforced heat cure acrylic resin and some other properties. $J$ Bagh Coll Dent 2010;22(3):1-6.

9. Gad M, Founda S, Al-Harbi F, Napankangas $\mathrm{R}$, Raustia A. PMMA denture base material enhancement: A review of fiber, filler, and nanofiller addition. Int $\mathrm{J}$ Nanomedicine 2017;12:3801-12.

10. McCabe J. Applied dental material. $9^{\text {th }}$ ed. UK: Blackwell Publishing Ltc. 2008. h. 120.

11. Sakaguchi R, Powers J. Craig's restorative dental materials. $12^{\text {nd }}$ ed. Texas Elsevier 2009. h. 84,178.

12. Pentapati L, Srinivas K, Shankar R, Swetha V, Krishna M. Effects of addition of aluminum oxide on flexural strength and hardness of acrylic resins. IOSR J Dent Med Sci 2017;16(3):1-6.

13. Yadav N, Elkawash H. Flexural strength of denture base resin reinforced with aluminum oxide and processed by different processing techniques. J Adv Dent Res 2011;2(1):33-6.

14. Sehajpal S, Sood V. Effect of metal filler on same physical properties of acrylic resin. J Prosthet Dent 1989;61(6):746-51.

15. Elboraey A, Dehis W, Mousa M. Flexural and tarike strength of acrylic resin denture base materials processed by three different methods. RJPBCS 2016;7(3):2556-62.

16. Alla R, Sajjan S, Alluri V, Ginjupalli K, Upadhya $\mathrm{N}$. Influence of fiber reinforcement on the properties of denture base material. JBNB 2013;4:91-7.

17. Pratama A, Waskito, Syahrul. Pengaruh kekasaran permukaan terhadap kekuatan tarik baja AISI 4140. J Pendidik Teknik Mesin 2016; 1-9.

18. Hashem M, Alsaleem S, Assery M, Abdeslam E, Vellappally S, Anil S. A comparative study of the mechanical properties of the light-cure and conventional denture base resins. OHDM 2014;13(2):311-5.

19. Salih S, Oleiwi J, Hamad Q. Investigation of fatigue and compression strength for the PMMA reinforced by different system for denture application. Int $\mathrm{J}$ Biomed Mater Research 2015;3(1):5-13.

20. Ghaffari T, Hamedirad F, Ezzati B. In vitro 
Pengaruh penambahan aluminium oksida terhadap kekuatan tarik dan tekan (Rahmadita dkk.)

comparison of compressive and tensile strengths of acrylic resins reinforced by silver nanoparticles at $2 \%$ and $0.2 \%$ concentrations. J Dent Res Dent Clin Dent Prospects 2014; 8(4):204-9. 